\title{
Prática Pedagógica e o Desenvolvimento da Consciência Fonológica
}

\section{Teaching practice and phonological awareness development}

\section{Cristiane Santos Lima Camilo*}

Universidade Salgado de Oliveira - UNIVERSO, Rio de Janeiro, Rio de Janeiro, Brasil.

\section{Márcia Maria Peruzzi Elia da Mota**}

Universidade Salgado de Oliveira - UNIVERSO, Rio de Janeiro, Rio de Janeiro, Brasil.

\begin{abstract}
RESUMO
Há bastante consenso na literatura PSI de que a consciência fonológica traz uma importante contribuição para a alfabetização. Surpreendentemente, poucos estudos têm avaliado o efeito das práticas de ensino na educação infantil, no que diz respeito ao efeito no desenvolvimento da consciência fonológica. O presente estudo investigou a relação entre as práticas de ensino, o desenvolvimento da consciência fonológica e do conhecimento do nome das letras. Duas classes de aula foram observadas. Participaram do estudo 33 crianças. As crianças que tiveram a professora que gastou mais tempo com atividades como ler estórias e trabalhar com a consciência fonológica foram as que tiveram maior ganho na consciência fonológica. Não foram encontradas diferenças significativas para o conhecimento do nome das letras. As implicações educacionais são discutidas.
\end{abstract}

Palavras-chave: Consciência fonológica, Letras, Metalinguagem, Ensino.

\begin{abstract}
There is quite a lot of agreement in the literature that phonological awareness is a important contributor to literacy acquisition. Surprisingly, little research has look at the teaching practice in pre-school regarding phonological awareness development. The present study investigated the relationship between teaching practice and development of phonological awareness and letter knowledge. Two classrooms were observed. Thirty three children partipated. The results showed that children at the teacher's class that spent more time with literacy activities such reading stories, working with phonological awareness were the ones that have greater improvement in phonological awareness knowledge. There were no significant results for letter knowledge. Educational implications were discussed.
\end{abstract}

keywords: Phonological awareness, Letter, Metalanguage, Teaching. 


\section{I ntrodução}

Há bastante consenso na literatura PSI de que a consciência fonológica, habilidade de refletir sobre os sons que compõem a fala (CARDOSO-MARTINS, 1995) é um importante precursor da alfabetização. A consciência fonológica é parte das habilidades metalinguísticas, ou seja, da habilidade da criança manipular a língua como objeto do pensamento (GARTON; PRATT, 1989).

Estudos realizados em várias línguas têm demonstrado que as crianças que têm melhor desenvolvimento das habilidades metalinguísticas são também as crianças que terão melhor desempenho na alfabetização. Adicionalmente, estudos de intervenção mostram que a instrução explícita implementada no sentido de ajudar o desenvolvimento da consciência fonológica, especialmente quando associado ao conhecimento de letras, ajuda a melhorar o desempenho das crianças na leitura (BRADLEY; BRYANT, 1983; CAPOVILLA; CAPOVILLA, 1997; 2000; 2001; PLAZA; Cohen, 2003; 2004; TUNMER; 1990).

Dada, a importância da consciência fonológica para alfabetização é de se estranhar a escassez de estudos que se preocupam em verificar como essa habilidade tem sido trabalhada nas classes preparatórias para alfabetização. REGO (2005), por exemplo, esclarece que no Brasil, foram poucos os estudos que se preocuparam em investigar empiricamente os efeitos produzidos pelas inovações pedagógicas introduzidas na alfabetização de crianças a partir de 1980.

Um dos estudos pioneiros nessa direção foi produzido por Rego e Dubeux (1994 apud Rego, 2005). Este estudo comparou grupos de crianças de duas escolas públicas submetidas a metodologias de alfabetização diferentes. As escolas estavam situadas no mesmo bairro e em ambas escolas havia oferta de pré-escolar, isto é, as crianças ingressaram na escola aos quatro anos de idade. Na escola 1 as crianças de pré-escolar não estavam expostas a atividades de leitura e escrita, apenas se cuidava de trabalhar a tradicional prontidão para a alfabetização, através de atividades de coordenação motora e da discriminação visual e auditiva. Enquanto na escola 2 foi realizada uma intervenção pedagógica que alterou a forma como se trabalhava a preparação para a alfabetização propriamente dita. A estruturação pedagógica da intervenção foi feita a partir de três eixos: leitura diária de histórias desde o início da educação infantil, atividades de escrita de palavras que as crianças estavam interessadas em aprender e atividades de estímulo à consciência fonológica, feita por meio de jogos que evidenciavam as semelhanças e as diferenças sonoras entre as palavras.

Os resultados foram levantados e mostraram um melhor desempenho em leitura e escrita das crianças que haviam atingido o nível alfabético (algum conhecimento das correspondências entre letra e 
som) na escola 2. Esse desempenho era significativamente superior ao do observado na escola 1.

Outro estudo pioneiro sobre a prática pedagógica foi realizado por Cardoso-Martins e Soares (1989), que examinaram duas questões. Em primeiro lugar, investigaram o nível de desenvolvimento da consciência fonológica de crianças das classes populares, relativo ao nível de desenvolvimento dessa habilidade apresentado por crianças da classe média e alta. Em segundo lugar, compararam a experiência escolar de crianças das classes populares com a de crianças da classe média e alta. Foram feitas entrevistas com professoras dos dois tipos de escola e a frequência de ocorrência das atividades que desenvolviam a consciência fonológica foram computadas.

No estudo das autoras citadas, as crianças das classes populares apresentaram um nível de desenvolvimento da consciência fonológica inferior ao das crianças da classe média alta. Os resultados obtidos sugerem que esta diferença resulta, em parte, de diferenças na experiência escolar dos dois grupos de crianças. A análise dos registros das entrevistas determinou a frequência de atividades que contribuem para o desenvolvimento da consciência fonológica nas diferentes escolas. Os dados obtidos não revelaram diferenças entre as escolas públicas e as escolas particulares em relação aos tipos de atividades desenvolvidas para favorecer a alfabetização. As duas escolas incluíram exercícios propícios ao desenvolvimento da consciência fonológica no seu programa pedagógico. Porém, as escolas que atendem a crianças das classes populares diferiu das escolas da classe média e alta em relação à frequência com que esses exercícios eram implementados. Essas escolas realizaram menos atividades de desenvolvimento da consciência fonológica.

Embora no contexto brasileiro não se observem muitos estudos que investiguem essa questão, em inglês alguns estudos tentaram verificar o papel da escolarização no desenvolvimento da consciência fonológica. Um estudo que cabe ressaltar foi realizado po Raz e Bryant (1989), que mostraram que as crianças de baixa renda e de classe média ingressam na escola com os mesmos níveis de consciência fonológica, mas na medida em que as crianças avançam na escolarização as crianças de baixa renda começam a ter escores inferiores ao das crianças de classe média. Os autores sugerem que as experiências com a escrita diferenciada dessas crianças pode ser a responsáveis pelas diferenças em desempenho.

$\mathrm{Na}$ pesquisa de Soares e Cardoso-Martins (1989) exercícios de identificação e produção de rima e aliteração ou exercícios de segmentação de palavras em sílabas, foram incluídos no cálculo da frequência das atividades favoráveis ao desenvolvimento da consciência fonológica. Estudos recentes têm chamado atenção para a necessidade de se incluir não só a frequência de atividades quando se está avaliando as práticas de ensino, mas também, quanto tempo 
foi gasto nessas atividades (PIASTA; CONNOR; FISHMAN; MORRISON, 2009). Nesse sentido, o presente estudo apresenta um diferencial. A frequência de atividades realizadas na escola que desenvolvem a consciência fonológica e alfabetização foi avaliada pelo tempo gasto, uma variável continua, e não como o simples computo da frequência de atividades, uma variável discreta. Incluiuse também uma segunda variável que tem aparecido na literatura como importante para aquisição da leitura e escrita: o conhecimento do nome das letras.

Apesar dos estudos ainda serem escassos sobre esse tema, o conhecimento do nome das letras parece ajudar a criança a aprender o princípio alfabético, pois muitas as crianças precisam aprender a conectar os sons as letras (princípio alfabético). Estudos nessa área mostram, também, que o nível salábico proposto por Ferreiro \& Teberosky (1979) pode ser explicado pelo conhecimento do nome das letras. A representação do "b" em "bba" ('beba') pode ser uma representação da letra e não da sílaba (CARDOSO-MARTINS; BATISTA, 2005; CORREA; CARDOSO-MARTINS; RODRIGUES, 2010). Desta maneira o presente estudo tem como objetivo preencher uma lacuna na literatura da área. Ao investigar o papel da prática pedagógica no desenvolvimento da consciência fonológica incluindo como variável o tempo gasto e também ampliando o número de estudos sobre o conhecimento do nome das letras pelas crianças em educação infantil.

\section{Método}

\subsection{Participantes}

A pesquisa foi desenvolvida em duas turmas de 3 o período de uma escola pública situada em um bairro do município de Niterói, que atende uma clientela de classes populares. A amostra consistiu de 33 alunos com idades de 4 a 5 anos: 16 da turma le 17 crianças da turma 2. O critério de inclusão na pesquisa foi a assinatura pelos responsáveis da criança de um termo de consentimento livre e esclarecido. Assim, participação no projeto foi voluntária e dependeu da assinatura do Termo de Consentimento Livre e esclarecido do comitê de ética em pesquisa. As crianças que tiveram essa autorização foram submetidas à pesquisa.

\subsection{Materiais}

Tarefas de consciência fonológica 


\subsubsection{Roteiro de avaliacão da consciência fonológica} (Santos, 1996)

Essa é uma tarefa de consciência fonológica que teve como objetivo verificar a dificuldade da criança em reconhecer o som inicial, final e o do meio das palavras. Cada item foi organizado em três séries, cada uma com três itens de prática e cinco de teste. Primeiramente a criança foi solicitada a identificar entre três palavras diferentes (palavras-teste), a qual iniciou com a mesma unidade de som que uma palavra-estímulo. Exemplificando: o som inicial "copo" (palavraestímulo) entre as palavras testes "cobra-sapo-lata". Aconteceu da mesma forma com as outras séries, só que com os sons finais e os do meio respectivamente. Foi dado um ponto para cada acerto e zero para cada erro, podendo a criança atingir o total máximo de 15 pontos.

\subsubsection{Conhecimento do nome das letras}

Conhecimento do nome das letras. Uma tarefa similar a de CardosoMartins e Batista (2005) foi aplicada. O examinador apresentou um cartão com as letras do alfabeto dispostas em ordem aleatória e pediu a criança para nomear cada uma delas. Apenas letras maiúsculas foram utilizadas, uma vez que as crianças em idade préescolar têm mais familiaridade com as letras maiúsculas do que com as letras minúsculas. Para este estudo foram selecionadas 22 letras sorteadas aleatoriamente do alfabeto português. Um ponto foi dado para cada acerto. O máximo de acerto possível nessa tarefa foi 22.

\subsubsection{Vocabulário - Wechsler Intelligence Scale for Children - WISC III (Wechsler,1991)}

O Sub-teste de Vocabulário foi administrado e corrigido de acordo com as especificações do manual (Wechsler, 1991). Os escores ponderados não foram utilizados nas análises estatísticas, pois não há normas para a faixa etária do grupo estudado. Utilizou-se o escore bruto, dando-se 1 ponto para cada resposta correta.

\subsubsection{Diário de atividades}

Um diário de atividades que envolvem as práticas de ensino, atividades mais frequentes realizadas na educação infantil, ligadas a alfabetização e ao letramento, bem como a atividades metalinguísticas foi elaborado para facilitar a observação das atividades de linguagem oral e escrita realizadas na escola respeitando a faixa etária das crianças. Esta lista foi discutida com o orientador e as duas professoras dessa série escolar para garantir a 
compatibilidade das atividades listadas com as que foram de fato realizadas na escola. A lista de atividades final incluiu seis atividades principais que envolvem alfabetização, letramento e desenvolvimento metalinguístico: trabalhos com letras, contar e ouvir estórias, rodinha (expressão oral), trabalho com rimas e atividade de escrita. Conforme será detalhado no procedimento, o diário era preenchido pelo examinador, com base nas suas observações das atividades realizadas na sala de aula.

\subsection{Procedimentos}

O projeto foi submetido ao comitê de ética da Universidade Salgado de Oliveira. Após todos os procedimentos éticos terem sido cumpridos, iniciou-se o estudo. O projeto foi realizado em duas etapas. A primeira etapa foi desenvolvida com intuito de investigar as práticas de ensino de cada profissional, e avaliar o nível de desenvolvimento metalinguístico-linguístico das crianças com a aplicação do teste de consciência fonológica, conhecimento das letras e de inteligência. As práticas de ensino foram investigadas com 0 preenchimento do diário por parte do examinador que verificou o tempo gasto nas atividades desenvolvidas nas classes de Educação Infantil. A segunda etapa dessa pesquisa foi realizada através da aplicação do teste de conhecimento das letras e de consciência fonológica. Esses testes envolviam a aplicação das tarefas às crianças novamente no segundo semestre.

As turmas selecionadas foram observadas durante o primeiro e segundo semestre de 2011 pela autora do projeto e um aluno de Iniciação Científica devidamente treinado. Cada uma delas foi observada uma vez por semana durante dois meses, totalizando 10 observações. Durante essas observações o examinador registrava a hora de início e de término das atividades no diário que havia sido preparado previamente com a lista das atividades relevantes ao tema que deveriam ser observadas.

Assim, os dados levantados incluem o registro de atividades que envolveram o tema: consciência fonológica, linguagem e escrita desenvolvidas dentro e fora da sala de aula, tendo início com a chegada dos alunos na escola e se término até finalizar o dia. Após a observação 0 tempo de ocorrência dessas atividades era contabilizado.

Cabe ressaltar, que previamente ao início da pesquisa foi feita uma observação piloto em uma escola, e uma turma que atendia a faixa etária selecionada para essa pesquisa, durante dois dias, nos quais se delineou uma lista de atividades que foi usada.

\section{Resultados}


Durante a observação das turmas verificou-se o tempo gasto nas seis atividades que envolvem o desenvolvimento do letramento e da alfabetização: trabalhos com letras, contar e ouvir estórias, rodinha (expressão oral), trabalho com rimas e atividade de escrita. O tempo foi medido em minutos ao longo das 10 Observações. A tabela 1 mostra o somatório do tempo gasto em cada turma. A análise das médias sugere que houve diferença na prática pedagógica realizada pelas duas professoras. A tabela indica que a turma 2 dispôs de mais tempo em atividades relacionadas a consciência metalinguística, letramento e alfabetização que a turma 1 . Tanto na turma 1 como na 2 , outras atividades que aparecem regularmente na prática da educação infantil, como por exemplo, atividades artesanais, musicais entre outras foram realizadas pelas professoras. O tempo dessas atividades foi maior na turma 1.

Um teste $\mathrm{t}$ para medidas repetidas foi realizado para verificar se houve diferença estatisticamente significativa entre a média de tempo gasto nas turmas. O teste $\mathrm{t}$ mostrou uma diferença significativa para turmas $\left(\mathrm{t}_{(10)}=-2,6, \mathrm{P}<0,05\right)$, indicando que a turma 2 teve significativamente mais tempo nas atividades dessa natureza do que a turma 1.

Partimos para a segunda etapa do trabalho que foi verificar se há uma relação entre a prática e o desenvolvimento da consciência fonológica das crianças. Para verificar se há uma relação entre o desempenho na consciência fonológica e a frequência de atividades de linguagem e escrita realizadas na escola, foi conduzida, primeiramente, um pré-teste para avaliar o nível inicial de consciência fonológica, vocabulário e conhecimento das letras das crianças. O vocabulário foi medido pelo número de palavras reconhecidas (escore bruto), pois não havia normas para essa idade. A Tabela 2 dá a média e desvio padrão para essas medidas. Não houve diferença estatisticamente significativa na média do vocabulário para as duas turmas, tendo o resultado do teste sido: $\mathrm{t}_{(31)}=-0,19, \mathrm{P}=0,8$.

No caso da consciência fonológica as turmas diferiram. É importante discutir o fato das médias iniciais não serem iguais para a consciência fonológica e uma turma ter média superior. Não houve manipulação experimental dos grupos e as observações respeitaram a realidade vigente do cotidiano escolar. Assim, a turma 2 obteve média superior a da turma 1 conforme descrito na Tabela 2 . O resultado do teste $t$ comparando a média das turmas foi significativa $\left(\mathrm{t}_{(31)}=-4,1, \mathrm{P}\right.$ $<0,001$ ) e confirma essa observação. Dessa forma, era importante que se controlasse o nível inicial da consciência fonológica para que se pudesse verificar se a prática pedagógica teve um efeito no desempenho dessa habilidade e que possíveis mudanças encontradas posteriormente não pudessem ser atribuídas a essas diferenças 
iniciais. Isso foi feito por meio de uma análise de covariância. A covariável foi o nível inicial de consciência fonológica. O resultado da análise de covariância mostrou que quando esse nível inicial era controlado, a diferença entre as turmas, embora no limite, é significativa $\left(F_{(1,31)}=4,1, P=0,05\right)$, a covariável consciência fonológica foi também significativa $\left(F_{(1,31)}=9,0, P<0,005\right)$. Assim, os resultados indicam que a turma que recebeu mais atividades de alfabetização e letramento teve um desempenho melhor do que a que recebeu menos.

Para o conhecimento das letras do alfabeto, o grupo 2 também apresentou conhecimento bem superior ao 1, conforme indicado na Tabela 1. Analisando o padrão de evolução das médias ao longo do tempo verificamos uma mudança contrária a esperada pela nossa hipótese. Houve um pequeno declínio no grupo 2 e um pequeno aumento no grupo 1. Para explicar esses resultados os dados brutos foram inspecionados e verificou-se que uma criança do grupo 1 teve um aumento de escore de reconhecimento de 5 letras para 22, apresentando um desenvolvimento atípico quando comparado ao grupo. Ao se fazer a análise das médias sem essa criança o padrão dos dois grupos fica igual e apresenta um pequeno declínio (ver Tabela 3). Cabe ressaltar que mesmo com a criança que apresenta grande progresso no conhecimento no nome das letras 0 desempenho da turma 1 ainda é bem inferior ao da turma dois, com as crianças reconhecendo menos da metade das letras. $\mathrm{O}$ teste $\mathrm{t}$ realizado nos dados completos não mostrou diferença significativa entre as turmas depois da covariável nível inicial das letras ter sido controlado $\left(F_{(1,31)}=0,07, P=0,7\right)$. A covariável nível inicial das letras foi significativa $(F(1,31)=25,0, P<0,001)$. Assim, para 0 conhecimento das letras do alfabeto as diferenças na prática não parecem ter um efeito no desempenho dos alunos.

Tabela 1: Somatório do tempo gasto em minutos ao final das 10 observações do Diário de Atividades

\begin{tabular}{|c|c|c|}
\hline \multirow[t]{2}{*}{ Atividade } & Turma 1 & Turma 2 \\
\hline & $\begin{array}{l}\text { Tempo } \\
\text { Total } \\
\end{array}$ & $\begin{array}{l}\text { Tempo gasto } \\
\text { Total }\end{array}$ \\
\hline Rodinha & 70 & 120 \\
\hline Escrita & $15 \mathrm{~m}$ & $60 \mathrm{~min}$ \\
\hline Letras & $60 \mathrm{~m}$ & $70 \mathrm{~m}$ \\
\hline Rima & $45 \mathrm{~m}$ & $90 \mathrm{~m}$ \\
\hline Ouvir Historia & 0 & $75 \mathrm{~m}$ \\
\hline Contar História & $30 \mathrm{~m}$ & $60 \mathrm{~m}$ \\
\hline Média (d.p) & $36,7(26,7)$ & $79,17(22,9)$ \\
\hline
\end{tabular}


Tabela 2

\begin{tabular}{lrrrrr}
\hline Turma & Letras & \multicolumn{1}{c}{$\begin{array}{c}\text { Letras } \\
2\end{array}$} & $\begin{array}{c}\text { Consciência } \\
\text { Fonológica }\end{array}$ & $\begin{array}{r}\text { Consciência } \\
\text { Fonológica 2 }\end{array}$ & WISC \\
\hline Turma & 4,56 & 5,56 & 7,81 & 6,93 & 4,81 \\
1 & $(1,78)$ & $(5,37)$ & $(1,93)$ & $(2,88)$ & $(2,00)$ \\
Turma & 15,05 & 14,13 & 10,88 & 11,26 & 4,94 \\
2 & $(6,33)$ & $(6,74)$ & $(2,26)$ & $(1,98)$ & $(1,74)$ \\
\hline Total & 9,96 & 9,70 & 9,39 & 9,03 & 4,87 \\
& $(7,06)$ & $(7,39)$ & $(2,59)$ & $(3,29)$ & $(1,84)$ \\
\hline
\end{tabular}

Tabela 3

\begin{tabular}{llrr}
\hline Turma & & Letras & \multicolumn{1}{c}{ Letras } \\
& & & 2 \\
\hline Turma 1 & Média & 4,53 & 4,46 \\
& DP & 1,84 & 3,22 \\
Turma 2 & Média & 15,05 & 14,13 \\
& DP & 6,33 & 6,74 \\
\hline
\end{tabular}

\section{Discussão}

A literatura internacional tem demonstrado a importância dos programas de avaliação do impacto das práticas de ensino para melhorar o desempenho dos alunos (PIASTA, CONNOR, FISHMAN, \& MORRISON, 2009). A literatura nacional, por outro lado, carece de estudos a esse respeito. Nesse sentido, a presente pesquisa, vem explorar uma lacuna na literatura da área. Esse estudo investigou a relação entre a prática pedagógica e o desenvolvimento de duas habilidades identificadas como precursoras da alfabetização: a consciência fonológica e o conhecimento do nome das letras.

Evidências de que as experiências com a escrita afetam o desempenho na consciência fonológica foram obtidas por Raz e Bryant (1990) no inglês. O estudo desses autores nos faz pensar sobre o que acontece durante a escolarização que promove 0 desenvolvimento das crianças de classe média de forma mais efetiva do que as de classe popular. A análise dos dados obtidos no presente estudo pode ajudar a contribuir para pensarmos essa questão.

O resultado pode ser discutido tanto em relação ao cotidiano escolar, em relação àquilo que de fato está sendo realizado na escola quanto em relação ao impacto dessa prática no desempenho dos alunos. Do ponto de vista das atividades realizadas na escola, nos reportamos aos dados da pesquisa pioneira sobre a experiência escolar de crianças brasileiras das classes populares e da classe média-alta, realizada por Magda Soares e Cláudia Cardoso (1989) citada na 
introdução. Esse estudo nos revelou que os dois tipos de escolas estudados incluíram exercícios propícios ao desenvolvimento da consciência fonológica, no seu programa de preparação para a alfabetização. Porém, o que merece ser destacado, é que as escolas que atendem as crianças das classes populares diferiram das escolas da classe média-alta em relação à frequência com que esses exercícios eram implementados. Comparando o nosso estudo com ao das autoras, destacamos que mesmo numa escola, que atende a uma mesma clientela há também muita variação em relação à frequência de atividades de letramento, alfabetização e linguagem realizadas pelas professoras.

Essa questão se torna mais importante quando verificamos que o tempo gasto pelos professores nas atividades pedagógicas está associado ao desenvolvimento da consciência fonológica. Depois, de se retirar a contribuição inicial da consciência fonológica, houve diferenças nas turmas quando ao desenvolvimento dessa habilidade no segundo semestre. A turma que recebeu mais tempo de instrução em atividades ligadas a linguagem oral e escrita foi a que teve 0 maior crescimento da consciência fonológica. Como inicialmente as crianças não diferiram quanto ao vocabulário, pode se esperar que essas diferenças não resultam de uma habilidade maior com a linguagem.

Em relação ao conhecimento das letras inicialmente observou-se um padrão das médias contrário ao da hipótese levantada. No entanto, a inspeção das médias mostrou que uma criança, com desenvolvimento atípico, estava "puxando" a média da turma 1 para cima. Ao se retirar essa criança observou-se que houve um pequeno declínio no desempenho das crianças. Não sabemos explicar o porquê dessa variação. De qualquer forma, como o resultado da análise estatística, mesmo com os escores totais não foi significativo, é possível que a variação nas médias tenha ocorrido pelo acaso.

Assim, não se encontrou evidências que corroborassem a ideia que a prática afete 0 desempenho do conhecimento das letras. 0 conhecimento do nome das letras pode requerer um processo de instrução explícita desse conhecimento. Ao observarmos a Tabela 2 verificamos que o tempo gasto pelas duas professoras em atividades de escrita e de conhecimento de letras foi muito baixo. Variou entre 15 minutos e 1 h e 10 minutos divididos em 10 sessões, ou seja, 10 dias letivos. Isto é de 1,5 a 7 minutos por dia. É possível, que se um tempo maior fosse gasto nesse tipo de atividade, pudéssemos observar uma melhoria no desempenho das crianças.

Ao se verificar que aspectos da prática pedagógica produzem um impacto no desempenho dos alunos, programas de treinamento e formação continuada de professores poderão ser subsidiados com informações substanciadas pelas contribuições oriundas das pesquisas científicas. Nesse sentido, estudos empíricos como este que 
tentem estudar o impacto dessa prática no desempenho escolar são necessários e precisam ser encorajados.

Uma limitação do presente estudo foi o fato das turmas terem níveis iniciais de conhecimento diferentes. É possível que as diferenças encontradas no presente estudo tenham sido devidas ao nível inicial de conhecimento das crianças. A turma que teve mais tempo de atividades de escrita, foi também a que tinha melhor índices iniciais de letras e consciência fonológica. A professora poderia estar respondendo a capacidade dos alunos. Se este é o caso, algumas considerações precisam ser feitas.

A partir dessa consideração, devemos destacar que o tempo gasto em atividades de desenvolvimento da linguagem oral e escrita deveria ser maior na turma em que as crianças tinham um pior desempenho. Essas crianças são aquelas que justamente precisam da maior estimulação. Decorre desse argumento, que precisamos questionar a formação dos nossos professores. Como é feita pelo professor a avaliação do seu aluno? Por avaliação, entendemos as necessidades pedagógicas que a criança tem para desenvolver as competências e habilidades esperadas para sua faixa etária. 0 professor deveria ser capaz de identificar as fraquezas e potenciais de seus alunos e planejar suas atividades de acordo com as necessidades das crianças e não agir de uma forma reativa.

Em conclusão, o presente estudo apresentou uma tentativa de verificar esse impacto em um contexto ecologicamente válido, sem manipulações experimentais. Tais, estudos apresentam limitações, como tamanho da amostra e dificuldades de controle experimental, mas ao mesmo tempo apresentam dados que podem contribuir para a reflexão sobre as questões educacionais mais próximos da realidade escolar.

\section{Referências}

BRADLEY, L.; BRYANT P. Problemas de leitura na criança. Porto Alegre: Ed. Artes Médicas, 1997.

CARRAHER, C.; SCHLIEMANN, A. L. CARRAHER, D. W. S. Na vida, dez; na escola, zero: os contextos culturais da aprendizagem da matemática. Cadernos de Pesquisa, São Paulo, v.42, 79-86, 1982.

CARDOSO-MARTINS, C (Org.). Consciência fonológica e alfabetização. 1. ed. Petrópolis: Vozes, 1995.

CARDOSO-MARTINS, C.; BATISTA, A. C. E. (2005). O conhecimento do nome das letras e o desenvolvimento da escrita: Evidência de crianças falantes do português. Psicologia: Reflexão \& Crítica, Porto Alegre, v. 18, n. 3, 330-336.

CORREA, M; CARDOSO-MARTINS, C.; RODRIGUES, L. O Conhecimento do nome das letras e a sua relação com o 
desenvolvimento da escrita: evidência de adultos iletrados. Psicologia. Reflexão e Crítica, Porto Alegre, v. 23, n. 1, Apr. 2010. Disponível em: <http://www.scielo.br/scielo.php?script=sci_arttext\&pid=S0102$79722010000100019 \&$ Ing=en\&nrm=iso >. Acessado em 04 de Março de 2012.

CARDOSO-MARTINS, C.; SOARES, M. B. A Consciência fonológica de crianças das classes populares: O papel da escola. REVISTA BRASI LEI RA DE ESTUDOS PEDAGOGI COS, Brasília, v. 70, p. 8697, 1989.

CAPOVILLA, A.; CAPOVILLA, F. O desenvolvimento da consciência fonológica durante a alfabetização. Temas sobre o desenvolvimento, São Paulo, v. 35, n. 6, p. 15-21,1997.

CAPOVILLA, A.; CAPOVILLA, F. Efeitos do treino de consciência fonológica em crianças com baixo nível sócio-econômico. Psicologia: Reflexão e Crítica, Porto Alegre, v. 13 , n 1, p. 07-24, 2000. CAPOVILLA, A.; CAPOVILLA, F. Alfabetização e método fônico. São Paulo: Mnemom, 2001.

FERREIRO, E.; TEBEROSKY, A. Psicogênese da língua escrita. Porto Alegre: ARTMED.

GARTON, A.; PRATT, C. Learning to be literate. The development of spoken \& w ritten language. Oxford: Basil Blackwell, 1989.

PIASTA, S. B.; CONNOR, C. M.; FISHMAN, B.; MORRISON, F. J. Teachers' knowledge of literacy, classroom practices, and student reading growth. Scientific Studies of Reading, Philadelphia, v. 13, n. 3, 224-248, 2009.

PLAZA, M.; COHEN, $H$. The interaction between phonological processing, syntactic awareness, and naming speed in the reading and spelling performance of first-grade children. Brain and Cognition, London, v. 53, 257-292, 2003.

PLAZA, M.; COHEN, H. Predictive influence of phonological processing, morphological/syntactic skill, and naming speed on spelling performance. Brain and Cognition, London, v. 55, p. 368373, 2004.

RAZ, I. S.; BRYANT, P. Social background, phonologicalawareness and children's reading. British Journal of Developmental Psychology, Oxford, v. 8, n. 3, 209-225, 1990.

REGO, L. L. B. Alfabetização e letramento: refletindo sobre as atuais controvérsias, 2005. <http://portal.mec.gov.br/seb/arquivos/pdf/Ensfund/alfbsem.pdf>. Acesso em 15 fev. 2012.

TUNMER, W. The role of language prediction skills in beginning reading. New Zealand J ournal of Educational Studies, London, v. 25, n. 2, pp. 95-112, 1990.

WECHSLER, D. WISC-III: escala de inteligência Weschsler para crianças. São Paulo: Casa do Psicólogo, 1991. 
SANTOS, A. A. A. A influência da consciência fonológica na aquisição da leitura e escrita. In: Fermino Fernandes Sisto. (Org.). Atuação psicopedagógica e aprendizagem escolar. Petrópolis: Vozes, 1996, p. 213-247.

\section{Endereço para correspondência Márcia Maria Peruzzi Elia da Mota}

Rua Marechal Deodoro, 217, 2o andar, Centro, CEP 24030-060, Niterói - RJ, Brasil. Programa de Pós-Graduação em Psicologia da Universidade Salgado de Oliveira Endereço eletrônico: mmotapsi@gmail.com

\section{Cristiane Santos Lima Camilo}

Rua Marechal Deodoro, 217, 2o andar, Centro, CEP 24030-060, Niterói - RJ, Brasil. Programa de Pós-Graduação em Psicologia da Universidade Salgado de Oliveira Endereço eletrônico: crisdomlima@ig.com.br

Recebido em: 22/06/2012

Reformulado em: 04/04/2013

Aceito para publicação em: 04/04/2013

Acompanhamento do processo editorial: Adriana Benevides Soares

\section{Notas}

* Mestre em Psicologia Social pela Universidade Salgado de Oliveira. Graduada em Pedagogia e Psicologia. Especialista em Terapia de Família e Pedagogia Empresarial. Atua principalmente nos seguintes temas: psicologia, educação e educação a distancia. Tem experiência na área de Psicologia - Educação - Ensino Superior (Presencial e EAD). Servidora Pública do Município de São Gonçalo, atuando como Orientadora Pedagógica com alunos do Ensino Fundamental.

** Doutora em Psicologia. Membro coordenador do grupo de pesquisa do CNPq "Cognição e Contextos Sociais" do PPG em Psicologia Social da UERJ. É professora titular do Programa de Pós-Graduação em Psicologia da Universidade Salgado de Oliveira. É bolsista de produtividade nível 2 do CNPq. 